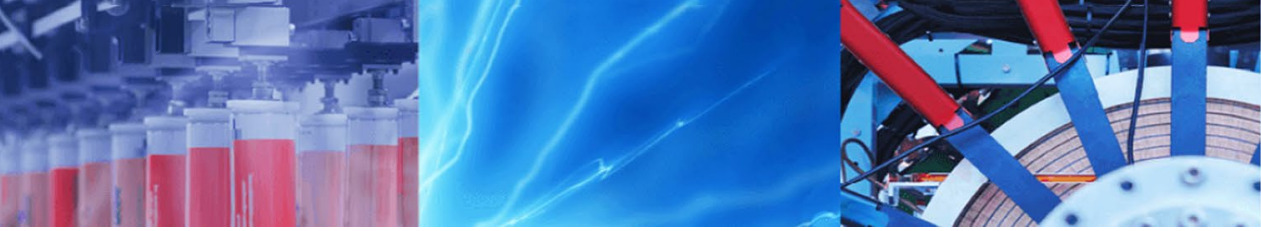

Research Article

\title{
Examining the polyphenol content, antioxidant activity and fatty acid composition of twenty-one different wastes of fruits, vegetables, oilseeds and beverages
}

\author{
Saranya Kuppusamy ${ }^{1,2,3} \cdot$ Kadiyala Venkateswarlu $^{4} \cdot$ Mallavarapu Megharaj ${ }^{2,3,5}$
}

Received: 19 November 2019 / Accepted: 6 March 2020 / Published online: 17 March 2020

(c) Springer Nature Switzerland AG 2020

\begin{abstract}
One of the most abundantly available, cost-effective valuable resources that are of all-time concern for minimization and economical re-utilization is food waste, and quantifying the phenolic compounds and identifying the principle chemical constituents will favour their industrial exploitation potential. Water, methanol and ethanol extracts of 21 common food wastes of four different classes (fruits, vegetables, oilseeds and beverages) were screened by determination of their antioxidant activity (measured by DPPH activity, reducing power and phosphomolybdenum method) as well as total phenol, flavonoid and ascorbic acid contents. Further predominant chemical constituents (essential fatty acid composition and elemental contents) of the top four phytochemical-rich food wastes were investigated by GC-MS and ICP-MS. Water was more efficient for polyphenol extraction, and ethanol extracts for antioxidant power. Onion peel, pineapple skin and date seed had the highest phenolic content and antioxidant activity. Radish peel showed the highest ascorbic acid content $(48.9 \pm 1.5 \mathrm{mg} / \mathrm{g})$. Onion peel emerged as a unique source of flavonoids ( $>80 \%)$. Onion peel, radish peel and pineapple skin were identified to be the sources of essential fatty acid, i.e., linoleic acid, particularly radish peel being the rich source of alpha-linoleic acid highlighting its potential for human dietary intake or as animal feed. Moreover, the screened polyphenol and unsaturated omega fatty acid-rich food wastes constituted considerable quantities of essential macro- and micronutrients. Our study demonstrates the possibility of recovering large amounts of natural phytochemicals from food wastes as alternatives to synthetics and for industrial applications.
\end{abstract}

Electronic supplementary material The online version of this article (https://doi.org/10.1007/s42452-020-2441-9) contains supplementary material, which is available to authorized users.

Saranya Kuppusamy, saran.miles2go@gmail.com | ${ }^{1}$ Centre for Environmental Studies, Anna University, Chennai 600025, India. ${ }^{2}$ Centre for Environmental Risk Assessment and Remediation (CERAR), University of South Australia, Mawson Lakes, SA 5095, Australia. ${ }^{3}$ Cooperative Research Centre for Contamination Assessment and Remediation of Environment (CRC CARE), PO Box 486, Salisbury South, SA 5106, Australia. ${ }^{4}$ Formerly Department of Microbiology, Sri Krishnadevaraya University, Anantapur 515055, India. ${ }^{5}$ Global Centre for Environmental Remediation (GCER), Faculty of Science and Information Technology, The University of Newcastle, Callaghan, NSW 2308, Australia. 


\section{Graphic abstract}

\section{'No more ONION PEEL, PINEAPPLE SKIN and DATE SEED are a waste, but a resource of commercial value and human utility.'}

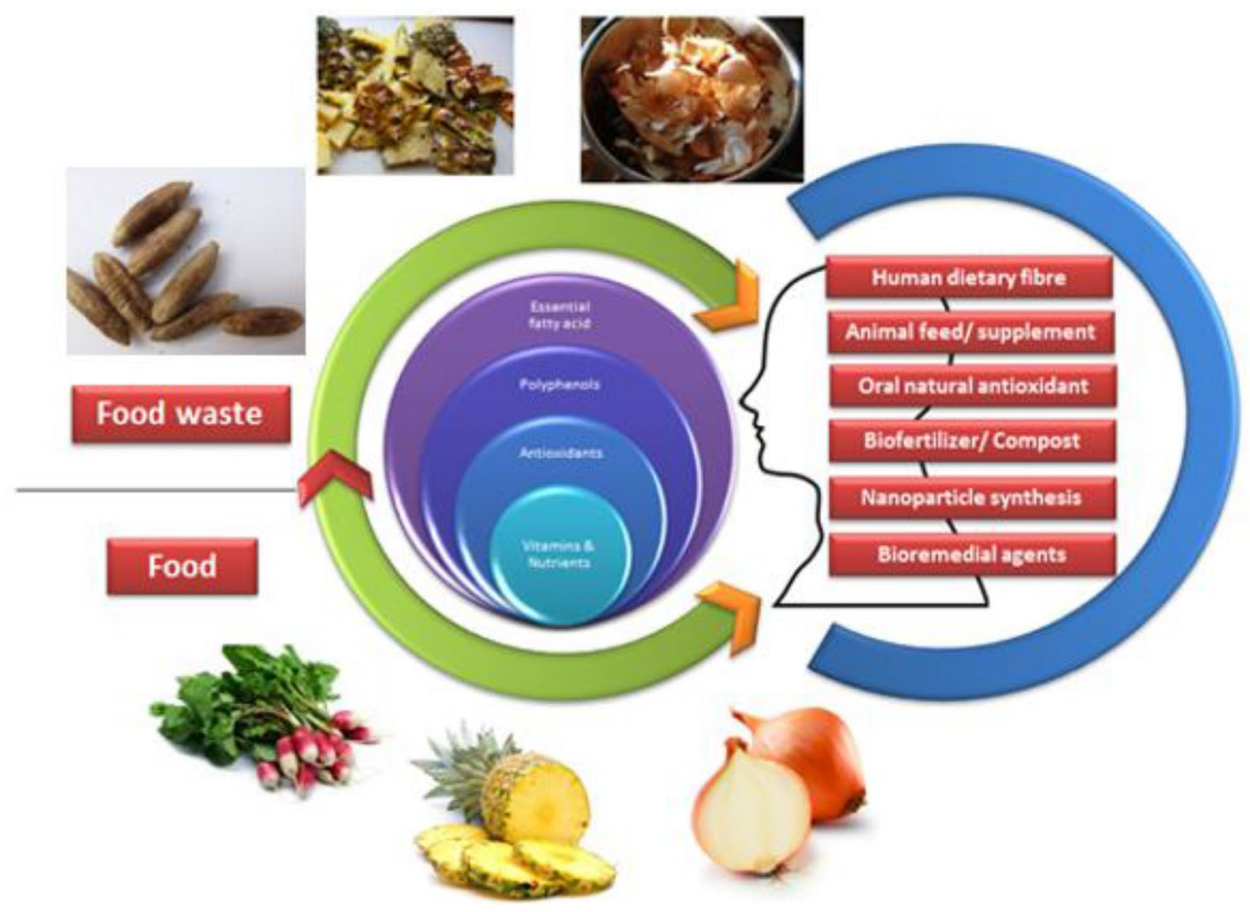

Keywords Food wastes · Phenols · Flavonoids · Ascorbic acid · Essential fatty acid · Elemental composition

\section{Introduction}

In 2011, the Food and Agricultural Organization estimated that nearly one-third (1.3 billion tons per annum) of global food production is never consumed and ends up as waste [1]. This would be ample to feed the estimated 3 billion starving human beings among the 7 billion current world populations. It is further estimated that $14 \%$ global carbon dioxide emission emanates from this food wastes, and thus, they represent an environmental problem for management locally, regionally and internationally. Organizations are thus now pointing out the need to understand this phenomenon. The united nation estimates that by 2050 the world population is expected to reach 9 billion people and food production to increase by $70 \%$ to meet the extra demand [2]. This will increase the mass of food wastes on the earth even more, leading to potentially alarming pollution impacts. If we are able to manage food wastes efficiently, then it will be easier to combat global warming and protect life on earth. There are already initiatives to prevent food wastage. Society's present primary concern, however, is largely an economic one.

In the light of the above issues, an effort was made in the present study to identify the natural polyphenol, ascorbic acid and essential fatty acid-rich food wastes with high antioxidant potential as these bioactive compounds are considered to have a beneficial effect on health. Industries and households are the major sources of food wastes, and detailed studies of those originating from these two sources, especially from the households, are meagre. Our study thus mainly focused on domestic food wastes along with some common industrial wastes such as pomace and pulp from agricultural by-products. Since fruits, vegetables, oilseeds and beverages are the most common food classes consumed and discarded daily either fresh or dry with intact phytochemical profiles, these four classes were considered for initial evaluation.

Evaluating the phytochemical compounds in green wastes gives the potential to use the biocompounds (phenols, flavonoids, tannins, flavonols, vitamin C, vitamin $\mathrm{E}$, 
essential fatty acid, etc.) or the antioxidant-rich sources in cosmetic, pharmaceutical and food industries as an alternative to the synthetic products. The latter are increasingly being rejected by consumers in the light of health-related issues. The most economical exploitation strategy for underutilized resources such as food wastes is to exploit them in the food production cycle by recognizing their potential. The most common re-utilization approach is the production of food supplements, oral antioxidants, dietary fibre concentrates or preservative food additives from biocompound-rich natural sources used in the foodprocessing industries. Moreover, radical scavengers and flavonoid-rich natural sources can be used as beneficial phyto-protection and anti-ageing ingredients in cosmetic products [3]. Another significance in assessing the biophenols is their value in fertilizer or compost production [4]. They are nutritionally rich with phytotoxicity and antimicrobial properties that can help to support environmental balance and sustainable agricultural production. Further, as dietary antioxidants afford protection against oxidative damage and are presumed to prevent various human diseases [5], there is also a wider prospect to produce medicines from these natural antioxidant-rich sources. Even nanoparticles can be synthesized from polyphenol-rich natural sources which can be directly used to remediate toxins in soil and aquatic ecosystems [6]. As green synthesis of nanoparticles is an emerging field in the environmental remediation sector, currently exploring the opportunities afforded by biophenols is of much importance [7]. On the other hand, biocompound-rich sources can be used as bioadsorbents of priority for remediation of emerging pollutants of concern in the biosphere [8].

Natural polyphenols/antioxidants and polyunsaturated fatty acid are found to be promising in the prevention of human heart, cancer, psychiatric and neurological diseases [9-11]. A study by Valente et al. [12] has found that polyphenols and polyunsaturated fatty acid in diet helps boost the production of the brain stem cells (new neurons). Extracts prepared from blueberry, cranberry, blackberry, raspberry and the isolated polyphenols from strawberry including quercetin, anthocyanins, kaempferol, esters of coumaric acid and ellagic acid, were found to have anticancer potential $[13,14]$. The inhibition of tumorigenesis by tea preparations and its polyphenol constituents such as epigallocatechin-gallate and theaflavin have also been reported [15]. Bioactive compound-rich natural resources have thus got potential for wide applications especially in biomedical applications [16].

From an overall economic and environmental perspective, in order to exploit underutilized wastes as valuable resources more extensively and effectively, it is timely to quantify the phenolic compounds and identify the principle chemical constituents. As domestic food wastes are the most abundant, feasible, cheap resources that could be explored and managed, our study evaluated and compared the useful properties of the phenolic fractions and antioxidant power of the most common food waste classes. Fatty acid and elemental composition of the screened phenolic antioxidant-rich food wastes were also elucidated in order to get a brief overview of a resourceful food waste that can be harnessed for commercial purposes.

\section{Materials and methods}

\subsection{Samples}

The samples investigated were the residues of $21 \mathrm{food}$ samples (fruits, vegetables, oilseeds and beverages) procured from local markets in South Australia. Powders of peel, skin, seed and spent coffee grounds were prepared from 14 of them. Pulp- and pomace-based powders were formulated from the remaining 7. Orange (Citrus sinensis), watermelon (Citrullus lanatus), honeydew (Cucumis melo), banana (Musa paradisica), butternut (Cucurbita moschata), pineapple (Ananas comosus), potato (Solanum tuberosum), onion (Allium cepa), radish (Raphanus sativus), garlic (Allium sativum) and peanut (Arachis hypogaea) were cleaned, manually peeled and the peels/rinds/skin/shell cut into small pieces and dried in a temperature-controlled room $\left(37^{\circ} \mathrm{C}\right)$ for two weeks. Subsequently, apple (Malus domestica), strawberry (Fragaria ananassa), plum (Prunus domestica), grape (Vitis vinifera), tamarind (Tamarindus indica), carrot (Daucus carota) and olive (Olea europaea) were grated, homogenized and filtered for separating the juice. The pomace or pulp left after juice extraction was dried in a forced air oven at $40^{\circ} \mathrm{C}$ for $72 \mathrm{~h}$. Similarly, date (Phoenix dactylifera) seed, spent coffee grounds (Coffea arabica) and tea (Camellia sinensis) leaves were also dried. After complete drying, the samples were finely ground with a coffee grinder to a particle size of approximately $0.5 \mathrm{~mm}$ and were stocked for further study in sealable polythene bags in a desiccator.

\subsection{Extraction procedures for polyphenol compounds and ascorbic acid}

Five $\mathrm{mL}$ of boiled water was added to $0.1 \mathrm{~g}$ of the sample, and the suspensions were left for $24 \mathrm{~h}$ in a shaker at room temperature $\left(24 \pm 2^{\circ} \mathrm{C}\right)$. The extracts were then centrifuged for $10 \mathrm{~min}$ at $3000 \mathrm{rpm}$ and the supernatant collected at $4{ }^{\circ} \mathrm{C}$ and used within $24 \mathrm{~h}$. Similarly, supernatants were saved by replacing boiled MQ water with methanol, ethanol and trichloroacetic acid. Extracts of water, ethanol and methanol were used to determine phenols, flavonoids and 
antioxidant activities of the selected food wastes. Ascorbic acid content of the selected samples was determined using the trichloroacetic acid extracts. All samples were extracted in duplicate. In all the experiments, the respective standard solution was used as the positive control. Methanol or water (instead of sample extract) was used as negative control.

\subsection{Determination of phenolic compounds}

\subsubsection{Total polyphenols (TP)}

Total polyphenol content was determined in all the water, methanol and ethanol extracts following a modified version of the Folin-Ciocalteu's method [17]. About $250 \mu \mathrm{L}$ of Folin-Ciocalteu phenol reagent was added to $100 \mu \mathrm{L}$ extract, and the mixture was kept at room temperature $\left(24 \pm 2{ }^{\circ} \mathrm{C}\right.$ ) for $5 \mathrm{~min}$. One $\mathrm{mL}$ of $20 \%$ sodium carbonate was added to the mixture and vortexed gently. The total volume of the mixture was then adjusted to $5 \mathrm{~mL}$ with $\mathrm{MQ}$ water. After the mixture had been kept at $24 \pm 2{ }^{\circ} \mathrm{C}$ for $45 \mathrm{~min}$, absorbance of the developed blue coloured complex was read spectrophotometrically at $660 \mathrm{~nm}$ against a blank, using a Synergy ${ }^{\mathrm{TM}}$ HT (Bio-Tek $^{\mathrm{R}}$ Instruments, Inc., Vermont, USA) Multi-Detection Microplate Reader. The standard calibration curve was plotted using gallic acid (25-1000 ppm) and the total polyphenol content expressed as gallic acid equivalents. Each result value was calculated as a mean of three determinations.

\subsubsection{Total flavonoids (TFd)}

Flavonoid content was measured by a modified spectrophotometric assay [18]. The reaction mixture comprised $100 \mu \mathrm{L}$ of extract, $100 \mu \mathrm{L}$ of $10 \%$ aluminium chloride and $100 \mu \mathrm{L}$ of $1 \mathrm{M}$ potassium acetate solutions. After $30 \mathrm{~min}$ incubation at room temperature, absorbance of the yellow coloured mixture was measured at $415 \mathrm{~nm}$ using a microplate reader. The total flavonoid contents were then calculated and expressed as quercetin equivalents.

\subsection{Screening of the extracts for antioxidant potential}

Natural polyphenols derived from plant materials are well known for their antioxidant potential [19], which does not result from a single mechanism but includes a wide range of reactions. As no one method can evaluate them all, it is typically recommended to use more than one technique to evaluate the antioxidant potential of samples. Thus, three different methods were employed as detailed below.

\subsubsection{DPPH radical scavenging activity (DPPH Inhibition)}

DPPH radical scavenging activity of the food waste extracts was evaluated according to a method outlined by Blois [20] with slight modifications. Briefly, $60 \mu \mathrm{M}$ of DPPH (2,2-diphenyl-1-picrylhydrazyl) radical solution in methanol was prepared and $3.9 \mathrm{~mL}$ of this solution mixed with $100 \mu \mathrm{L}$ of the sample solutions (containing their respective phenol fractions). After $30 \mathrm{~min}$, absorbance of the samples (As) was measured at $515 \mathrm{~nm}$. Blank samples containing $100 \mu \mathrm{L}$ of the respective extractant was simultaneously treated as above and its absorbance recorded as $A_{b}$. DPPH radical scavenging activity was then calculated using the formula given below:

$\% \mathrm{DPPH}$ inhibition $=\frac{A_{\mathrm{b}-A_{\mathrm{s}}}}{A_{\mathrm{b}}} \times 100$

\subsubsection{Reducing power $\left(P_{\mathrm{R}}\right)$}

Reducing power of phenolics present in the extracts was estimated using a method as described by Oyaizu [21]. About $100 \mu \mathrm{L}$ of extract, $500 \mu \mathrm{L}$ of phosphate buffer $(0.2 \mathrm{M}$, $\mathrm{pH} 6.6$ ) and $500 \mu \mathrm{L}$ of potassium ferricyanide (1\%) were vortexed gently and incubated at $37^{\circ} \mathrm{C}$ in a water bath. After $20 \mathrm{~min}, 500 \mu \mathrm{L}$ of trichloroacetic acid (10\%) was added to the mixture and the contents were centrifuged at $5000 \mathrm{rpm}$ for $10 \mathrm{~min}$. The upper layer $(500 \mu \mathrm{L})$ was then collected separately and mixed with $100 \mu \mathrm{L}$ of iron (III) chloride solution $(0.1 \%)$, and the absorbance measured at $700 \mathrm{~nm}$. Ascorbic acid was used as the standard. Increased absorbance of the reaction mixture signifies greater ferric to ferrous ion-reducing power of the food wastes tested.

\subsubsection{Total antioxidant activity by the phospho-molybdate method $\left(P_{M}\right)$}

The antioxidant activity was evaluated by the phosphomolybdate method of Prieto et al. [22], with slight modifications. The basic principle is the reduction of $\mathrm{Mo}(\mathrm{VI})$ to $\mathrm{Mo}(\mathrm{V})$ by the sample extract possessing antioxidant compounds. Briefly, an aliquot of $100 \mu \mathrm{L}$ of the sample solution was combined with $1 \mathrm{~mL}$ of the reagent solution $(0.6 \mathrm{M}$ sulphuric acid, $28 \mathrm{mM}$ sodium phosphate monobasic and $4 \mathrm{mM}$ ammonium molybdate) in Eppendorf tubes. For the blank, the respective extractant $(100 \mu \mathrm{L})$ was mixed with $1 \mathrm{~mL}$ of the reagent and the tubes were capped and incubated in a water bath at $95^{\circ} \mathrm{C}$ for $90 \mathrm{~min}$. After $90 \mathrm{~min}$, samples were cooled to room temperature and the absorbance measured at $695 \mathrm{~nm}$ against ascorbic acid. 


\subsection{Ascorbic acid (AA) content}

Vitamin C concentrations in the food waste trichloroacetic acid extracts were determined using the method of Roe and Kuether [23]. The supernatant $(500 \mu \mathrm{L})$ was mixed with $10 \mu \mathrm{L}$ of DTC reagent (3\% of 2, 4-dinitrophenylhydrazine, $0.4 \%$ of thiourea and $0.05 \%$ of copper (II) sulphate) prepared in $9 \mathrm{~N}$ sulphuric acid, vortexed gently and incubated at $37^{\circ} \mathrm{C}$ in a water bath for $90 \mathrm{~min}$. After incubation, the mixture was ice-cooled followed by the addition of $750 \mu \mathrm{L}$ of $65 \%(\mathrm{v} / \mathrm{v})$ sulphuric acid, and the absorbance of the mixture measured at $520 \mathrm{~nm}$. The results were expressed as ascorbic acid equivalents.

\subsection{GC and ICP-MS analysis}

Predominant chemical constituents of the top four phytochemical-rich food wastes were investigated by GC-MS. Briefly, hot water extract of the food wastes was acidified with few drops of concentrated $\mathrm{HCl}$, extracted by ultrasonication for $15 \mathrm{~min}$ (12 kHz sweep bandwith, Soniclean Pulse Swept ${ }^{@}$ Power Ultrasonicator, Soniclean Pty. Ltd., Australia) with methanol, filtered ( $0.4 \mu$ filter) and injected in a GC $5975 \mathrm{VL}$ mass selection detector equipped with triple axis detector (Agilent Technologies, USA). The GC injection port was configured for $1 \mu \mathrm{L}$ on-column injections, with an initial temperature of $50^{\circ} \mathrm{C}$, held for $5 \mathrm{~min}$, and ramped up to $260^{\circ} \mathrm{C}$ in $20 \mathrm{~min}$. The flow rate was $1.1 \mathrm{~mL} \mathrm{~min}^{-1}$ with a total run of $77.5 \mathrm{~min}$. An Agilent HP-5MS capillary column with $5 \%(\mathrm{v} / \mathrm{w})$ phenyl-substituted methyl siloxane nonpolar stationary phase, cross-linked and double bonded to the capillary wall with excellent thermal stability and low bleed levels was used. The dimension of the column was $30 \mathrm{~m} \times 250 \mu \mathrm{m} \times 0.25 \mu \mathrm{m}$. From the obtained chromatogram, the unknown compounds were identified by matching their specific retention time with the existing database. Compounds that presented more than $80 \%$ similarity with the existing database are only presented. Since majority of the food waste constituents were fatty acid, we observed fatty acid methyl esters as briefed in Table 3.

The phenol and essential fatty acid-rich food wastes were analysed for total carbon $(\mathrm{C})$ and nitrogen $(\mathrm{N})$ by dry combustion with a Trumac CN analyzer (Leco ${ }^{\circledR}$ Corporation, US). Subsequently, portion $(0.5 \mathrm{~g})$ of the food wastes were digested in triplicate with $5 \mathrm{~mL}$ aqua regia in a Teflon digestion vessel using a microwave accelerated reaction system (CEM-MARS $X^{\circledast}$ ) as outlined in US EPA method SW 3051. The total elemental (mineral) contents in diluted suspensions of the extracts were determined using a standard reference material (Montana soil SRM 271, Certificated by National Institute of Standards and Technology) and blank in an Agilent 7500c (Agilent Technologies, Japan) inductively coupled plasma mass spectrometer (ICP-MS).

\subsection{Statistical analysis}

All experimental results were reported as mean values with their corresponding standard deviations. Differences between variables were tested for significance by multivariate analysis and Tukey's test using SPSS (Statistical Program for Social Sciences, IBM ${ }^{\oplus}$ Corporation, USA) statistical software version 20. Differences at $p<0.05$ were considered to be significant. Pearson correlation coefficients $(r)$ were also calculated to assess the significance of correlations among variables again using SPSS software.

\section{Results and discussion}

\subsection{TP}

Polyphenols are the most significant fruit constituents by virtue of their antioxidant activity [24]. Table 1 summarizes the TP content in the water, methanol and ethanol extracts of the food residues. For all the extracts tested, the amount of TP in the fruit, vegetable, oilseed and beverage waste extracts ranged from 7-68, 9-105, 9-62 and 13-30 mg gallic acid/g dry sample, respectively. There are significant effects of different extractants on the TP content $(p<0.05)$; the highest was determined in the water extract for most samples analysed and was 1.1, 3.9 $\times$ higher than the TP values for the methanol and ethanol extracts. Polyphenol extraction by solvents like methanol and ethanol was observed to be best suited for peanut shell as well as spent tea leaves (1.8-2 $\times$ higher), and date seed and onion peel (1.5-3 $\times$ higher). The variability in TP content caused by different solvents may be due to the varying solubility of the phenolic compounds, which is directly related to the compatibility of the compounds with the solvent system. Even the nature of the sample (solidity, $\mathrm{pH}$, etc.) and extraction temperature can be factors that affect the solubility of the phenolic compounds. Overall, based upon the present TP data, it is assumed that the food wastes contain diverse phenolic compounds with different polarity, and water is a better extractant for polyphenols than the other polar protic solvents like methanol and ethanol. A study conducted by Peschel et al. [3] has demonstrated the possibility of recovering large amounts of phenolics with antioxidant properties from fruit and vegetable residues using water. However, in most cases, methanolic extraction of powders has been used to study the phytochemical profile of food wastes $[25,26]$.

Of the 21 food wastes considered, onion peel stands out clearly from the others in its high phenolic content (mean $75.6 \mathrm{mg} / \mathrm{g}$ ), followed in rank order by date seed $(47.7 \mathrm{mg} / \mathrm{g})>$ pineapple skin $(39.7 \mathrm{mg} / \mathrm{g})>$ olive pomace $\geq$ radish peel $\geq$ plum pomace $(30-32 \mathrm{mg} / \mathrm{g}$ ) extracts. 
Table 1 TP and TFd content in water, methanol and ethanol extracts of food wastes

\begin{tabular}{|c|c|c|c|c|c|c|c|c|}
\hline \multirow[t]{2}{*}{ Food waste } & \multicolumn{4}{|l|}{$\mathrm{TP}^{\mathrm{a}}$} & \multicolumn{4}{|l|}{$\mathrm{TFd}^{\mathrm{b}}$} \\
\hline & Water & Methanol & Ethanol & Mean & Water & Methanol & Ethanol & Mean \\
\hline \multicolumn{9}{|l|}{ (a) Fruits } \\
\hline Orange peel & $28.8 \pm 1.6$ & $19.1 \pm 2.8$ & $22.0 \pm 1.0$ & 23.3 & $5.1 \pm 0.7$ & $6.8 \pm 1.5$ & $8.8 \pm 1.2$ & 6.9 \\
\hline Watermelon rind & $15.1 \pm 2.8$ & $13.4 \pm 2.7$ & $8.1 \pm 1.5$ & 12.2 & $12.6 \pm 0.6$ & $3.5 \pm 0.7$ & $2.9 \pm 0.8$ & 6.3 \\
\hline Honeydew peel & $26.7 \pm 0.9$ & $24.7 \pm 0.8$ & $18.6 \pm 1.3$ & 23.3 & $7.1 \pm 0.7$ & $14.6 \pm 0.6$ & $17.2 \pm 2.7$ & 13 \\
\hline Banana peel & $27.1 \pm 0.8$ & $24.7 \pm 0.7$ & $20.0 \pm 0.2$ & 23.9 & $3.1 \pm 0.2$ & $5.0 \pm 0.3$ & $8.7 \pm 1.0$ & 5.6 \\
\hline Butternut peel & $20.1 \pm 1.2$ & $10.7 \pm 0.9$ & $7.9 \pm 2.5$ & 12.9 & $11.5 \pm 0.9$ & $4.3 \pm 1.2$ & $5.1 \pm 1.3$ & 7 \\
\hline Apple pomace & $27.5 \pm 1.0$ & $17.1 \pm 0.4$ & $7.6 \pm 0.6$ & 17.4 & $4.1 \pm 0.1$ & $6.9 \pm 0.2$ & $3.4 \pm 0.5$ & 4.8 \\
\hline Strawberry pomace & $37.5 \pm 1.8$ & $21.9 \pm 1.8$ & $13.8 \pm 2.8$ & 24.4 & $1.9 \pm 0.1$ & $4.9 \pm 0.07$ & $4.1 \pm 0.8$ & 3.6 \\
\hline Plum pomace & $51.8 \pm 0.5$ & $20.9 \pm 0.6$ & $17.6 \pm 0.1$ & 30.1 & $7.4 \pm 0.4$ & $6.0 \pm 0.4$ & $5.3 \pm 0.6$ & 6.2 \\
\hline Grape pomace & $36.8 \pm 0.7$ & $21.3 \pm 0.5$ & $15.2 \pm 2.1$ & 24.4 & $5.2 \pm 0.2$ & $4.7 \pm 0.3$ & $3.4 \pm 0.5$ & 4.4 \\
\hline Pineapple skin & $68.3 \pm 1.2$ & $28.6 \pm 1.5$ & $22.3 \pm 0.6$ & 39.7 & $15.3 \pm 0.2$ & $12.1 \pm 0.8$ & $9.8 \pm 2.0$ & 12.4 \\
\hline Tamarind pulp & $29.0 \pm 1.1$ & $14.2 \pm 2.4$ & $25.6 \pm 0.5$ & 22.9 & $7.2 \pm 0.4$ & $7.9 \pm 0.6$ & $6.6 \pm 0.7$ & 7.2 \\
\hline $\begin{array}{l}\text { Dates seed } \\
\text { (b) Vegetables }\end{array}$ & $37.2 \pm 1.1$ & $38.8 \pm 1.1$ & $67.0 \pm 5.0$ & 47.7 & $3.4 \pm 2.8$ & $2.9 \pm 2.4$ & $3.9 \pm 1.2$ & 3.4 \\
\hline Potato peel & $9.4 \pm 1.6$ & $10.4 \pm 0.2$ & $10.7 \pm 2.3$ & 10.2 & $2.3 \pm 0.9$ & $2.0 \pm 0.7$ & $4.2 \pm 0.1$ & 2.8 \\
\hline Onion peel & $35.7 \pm 5.1$ & $85.7 \pm 4.1$ & $105.2 \pm 1.3$ & 75.5 & $32.1 \pm 0.2$ & $76.7 \pm 0.1$ & $74.6 \pm 1.9$ & 61.1 \\
\hline Carrot pulp & $34.4 \pm 2.0$ & $15.9 \pm 1.6$ & $24.1 \pm 1.4$ & 24.8 & $5.3 \pm 0.2$ & $2.7 \pm 0.3$ & $8.1 \pm 0.5$ & 5.4 \\
\hline Radish peel & $44.6 \pm 0.6$ & $19.4 \pm 1.2$ & $29.9 \pm 1.5$ & 31.3 & $5.3 \pm 0.2$ & $2.0 \pm 0.6$ & $7.1 \pm 0.2$ & 4.8 \\
\hline $\begin{array}{l}\text { Garlic peel } \\
\text { (c) Oilseeds }\end{array}$ & $11.5 \pm 2.8$ & $10.5 \pm 1.8$ & $4.7 \pm 1.4$ & 8.9 & $2.1 \pm 0.7$ & $0.7 \pm 0.3$ & $1.4 \pm 0.7$ & 1.4 \\
\hline Olive pomace & $62.2 \pm 2.8$ & $16.0 \pm 2.5$ & $18.6 \pm 2.2$ & 32.3 & $10.5 \pm 0.2$ & $3.7 \pm 0.6$ & $8.4 \pm 0.3$ & 7.5 \\
\hline $\begin{array}{l}\text { Peanut shell } \\
\text { (d) Beverages }\end{array}$ & $11.5 \pm 0.8$ & $17.7 \pm 2.6$ & $9.7 \pm 2.0$ & 13 & $2.2 \pm 0.4$ & $9.0 \pm 0.3$ & $5.8 \pm 0.8$ & 5.7 \\
\hline Spent coffee grounds & $29.3 \pm 0.7$ & $26.5 \pm 0.9$ & $15.9 \pm 1.5$ & 33.9 & $5.7 \pm 1.9$ & $5.0 \pm 0.1$ & $9.7 \pm 0.7$ & 6.8 \\
\hline Spent tea grounds & $13.5 \pm 2.1$ & $30.1 \pm 1.8$ & $24.7 \pm 1.4$ & 22.8 & $2.9 \pm 0.07$ & $11.0 \pm 1.0$ & $12.2 \pm 1.3$ & 8.7 \\
\hline
\end{tabular}

${ }^{\mathrm{a}}$ In $\mathrm{mg}$ gallic acid/g

${ }^{\mathrm{b}}$ In mg quercetin/g

Garlic, potato and butternut peels and watermelon rind recorded the lowest. Since the sample preparation, extraction and determination procedures were exactly the same in all cases, the significant differences observed among their phenolic contents in this study is probably due to the intrinsic properties of the food wastes. These substantial differences in TP values of the food waste extracts tested are likely to account for the distinct antioxidant activities among the samples. In fact, there were no significant differences between some of the food wastes like spent tea leaves and coffee grounds, tamarind pulp, orange peel, honeydew melon peel, banana peel, strawberry pomace, grape pomace and carrot pulp (mean $23.5 \mathrm{mg} / \mathrm{g}$ ). Our TP values found in the food waste extracts were up to $4 \times$ higher than those previously reported in the literature. In the case of onion peel, a similar total phenol content of hot water extracts was reported by Lee et al. [27] and Singh et al. [28], although the values reported by the latter authors for onion peel methanol extracts were approximately $1.8 \times$ lower. Skerget et al. [29] observed similar values for ethanolic onion peel extracts. A wide range of TP contents was proposed for olive pomace water extracts [30] which was also in broad agreement with those reported in Table 1. However, Ardekani et al. [31] observed TP values considerably higher for date seeds than those reported in the present research $(6.8-11.6 \mathrm{mg} / \mathrm{g}$ as gallic acid equivalents). The TP value determined by Kalpna et al. [32] for pineapple extract was $2 \times$ lower than in this study. Singh and Rajini [33] reported $3.93 \mathrm{mg}$ gallic acid/g in potato peel extracts, $3 \times$ lower than the observation made in the present analysis. A similar report of a $3 \times$ lower TP value was made by Lu et al. [34] for garlic peel extracts. All of these differences could be attributed to the use of different extraction techniques and also to different varieties, geographic origin, growth conditions, and harvest season of samples tested as all these parameters affect the synthesis and accumulation of phenolic compounds in plant parts [35]. It is noteworthy that, apart from the samples of importance discussed above, data are not available for 
radish peel, watermelon rind and butternut peel water/ methanol/ethanol extracts.

\subsection{TFd}

Flavonoids are one of the widely distributed groups of plant phenolic compounds which are very effective antioxidants [36]. Our results for total flavonoid content of food waste extracts after aluminium chloride and potassium acetate reaction are shown in Table 1. Significant differences were noticed between the different food wastes tested and between the different solvents used for extraction. Ethanolic extracts showed better relationship with phenols $(r=0.63, p<0.05)$ than methanolic and water extracts. This might be due to more non-covalent interactions of ethanol with flavonoids [37] that would have resulted in a rapid diffusion of flavonoids in ethanol compared to methanol and water. Solubility of polyphenols depends mainly on the hydroxyl groups, molecular size and length of the hydrocarbon chains. This might also be the reason for ethanol being the best solvent for flavonoid extraction from plant materials as found by other authors [38]. Our extraction data varied between a mean minimum value of $1.4 \mathrm{mg}$ quercetin $/ \mathrm{g}$ for garlic peel and a maximum of $61.1 \mathrm{mg}$ quercetin/g for onion peel, quite similar to the trend observed for the total phenolic content of the food residues. The flavonoid content of the $21 \mathrm{sam}$ ples decreased in the following order: onion peel $>$ honeydew peel $\geq$ pineapple skin $>$ spent tea leaves $\geq$ olive pomace $\geq$ spent coffee grounds $\geq$ tamarind pulp $\geq$ butternut peel $\geq$ orange peel $>$ watermelon rind $\geq$ plum pomace $>$ peanut shell $\geq$ banana peel $\geq$ carrot pulp $>$ apple pomace $\geq$ radish peel $>$ grape pomace $\geq$ strawberry pomace $>$ date seed $\geq$ potato peel $>$ garlic peel. From all the food residues assessed, peels were shown to contain high amounts of flavonoids. Singh et al. [28] published the total flavonoid content of onion peel with 3.5-fold higher values for their water extracts. On the other hand, flavonoid concentration of the ethanolic extracts of onion peel is in line with the findings of Skerget et al. [29]. Kalpna et al. [32] reported a flavonoid concentration of $3.19 \mathrm{mg}$ quercetin/g in pineapple skin methanolic extracts nearly $3.8 \times$ lower than the results in this study. No quantifiable amounts of flavonoids were found in the garlic peel by Beato et al. [39]. In summary, total flavonoid results found in this study were three to fourfold higher than those reported in the literature for similar food residues. We believe that this is because of the use of different analytical methods and standards. One of the significant findings of this study is that the prime source of flavonoids among all the food wastes, onion peel, accounted for $>80 \%$ flavonoids among the total phenols detected. Flavonoids were also the major constituent in butternut peel, with a concentration of $>50 \%$ of the total phenols. In general, a weakly significant correlation was found between the total phenols and flavonoid content of the food residues $(r=0.55-0.63, p<0.05)$, which suggests that flavonoids are indeed one of the major phenolic compounds present in these food wastes.

\subsection{Antioxidant potential}

\subsubsection{DPPH radical scavenging activity}

DPPH is a widely used stable free radical to evaluate the antioxidant potential of a sample [40]. Comparison of the $\% \mathrm{DPPH}$ inhibition values for water, methanol and ethanol extracts of different food waste classes are shown in Table 2. Ethanol extracts significantly $(p<0.05)$ showed high DPPH radical scavenging activity for most of the extracts although they contain less total phenolics in these extracts compared to the water extracts. This might be because of the differences in the phenolic combinations [41], as the DPPH radical scavenging activity of a substrate depends upon its phenolic structure as well as the number and the location of the hydroxyl groups [42]. With a mean DPPH inhibition of 70\%, onion peel showed higher antioxidant capacity than that observed for garlic peel, which presented the lowest DPPH inhibition (mean: - 3.6\%). Significant differences $(p<0.05)$ were detected among the 21 food wastes evaluated. Similar to the total phenolic contents, three of the food residue extracts exhibited the highest antioxidant activity as indicated in the following rank order: onion peel $>$ date seed $\geq$ pineapple skin. All the remaining extracts other than garlic peel, potato peel, butternut peel, watermelon rind, apple pomace and peanut shell (means: -6.2 to $11 \%$ DPPH inhibition) exhibited intermediate antioxidant potential (means: $30-45 \%$ DPPH inhibition). The \%DPPH radical scavenging activity of onion peel found in this study is in accordance with the findings by Singh et al. [28] and Skerget et al. [29]. However, for tea waste, potato peel and strawberry pomace, the reports available in the literature [43-47] are values up to 20 -fold higher than those reported here. No reports are available in the literature for rest of the samples to enable comparison.

\subsubsection{Ferric and molybdenum reduction}

Their reducing property signifies that antioxidant compounds are electron donors and can thus reduce the oxidized intermediates of lipid peroxidation processes [48]. It is for this reason the ferric and molybdenum reducing properties of the food wastes were evaluated to screen the best source of antioxidants (Table 2). The measured antioxidant activity varied because each assay is based 


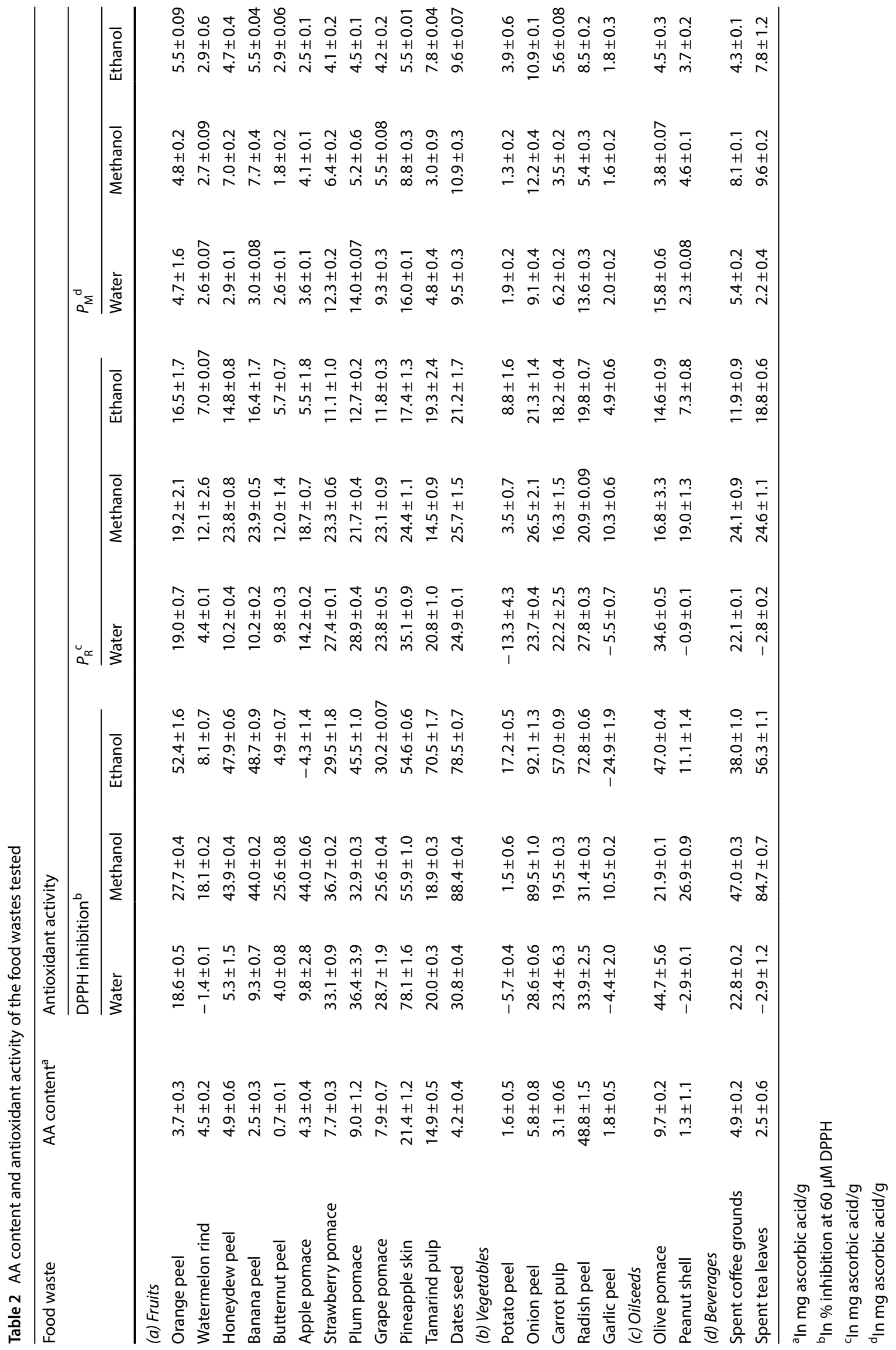


on different chemical reactions. The ferric reducing power and molybdenum reduction ranged from 0.37 to $25.9 \mathrm{mg}$ ascorbic acid/g dry sample and from 1.8 to $10.7 \mathrm{mg}$ ascorbic acid/g dry sample, respectively. Similar to DPPH inhibition, onion peel, date seed and pineapple skin exhibited the highest and garlic peel the lowest antioxidant potential. Overall, a similar pattern as the DPPH assay was observed with slight variations. However, in the ferric and molybdenum reduction assays, antioxidant activities of the water and methanol extracts were significantly $(p<0.05)$ greater than for the ethanol extracts. This might be due to the presence of more hydrophilic compounds in the water extracts [49].

\subsection{Ascorbic acid (vitamin C) content}

As ascorbic acid is one of the endogenous antioxidants found in plant parts [50], evaluation of its level in the selected food wastes was carried out using the DTC reagent; its monitored absorbance at $520 \mathrm{~nm}$ is presented in Table 2. Vitamin C content of the food residues varied from 0.7 to $48.8 \mathrm{mg}$ ascorbic acid/g sample on a dry weight basis, which represents a variation of about 69 -fold. Radish peel showed significantly $(p<0.05)$ the highest ascorbic acid content $(48.9 \pm 1.5 \mathrm{mg} / \mathrm{g})$ followed by pineapple skin and tamarind pulp. Butternut peel and peanut shell had the lowest antioxidant capacity. The total ascorbic acid content of the food residues is unrelated to the total polyphenol content or antioxidant potential. This suggests that vitamin $C$ is the minor antioxidant compound in most of the food residues tested. Further data are not available in the literature to compare the food wastes tested with the maximum or minimum ascorbic acid contents found elsewhere. In general only the vitamin C content of entire fresh fruits or vegetables is available. Compared to these, residues like peels and pulp have only $50-70 \%$ of the ascorbic acid contents. In spite of this, food wastes are clearly rich sources of vitamin $C$.

\subsection{Correlation between assays}

In order to evaluate the uniformity of the expression the activities of the food residues based on the three assays employed, Pearson's correlation coefficients were calculated. All correlations between the different methods revealed a significantly high, positive correlation $(r \geq 0.86$, $p<0.05)$, suggesting that they produce comparable values for their phenolic constituents and antioxidant potential. For the antioxidant assays, all the methods showed the highest correlation coefficients $(r=0.92$ to 0.996 , and $r=0.86$ to $0.998 ; p<0.05$ ) for all the solvents tested, although strong correlation was also observed for the ethanol extracts $(r>0.995, p<0.05)$. This strong correlation between the different methods might be due to the possibility of single-electron transfer in all the three methods, in spite of their unique mechanisms. A similar correlation was previously found by Dudonne et al. [51] for plant extracts. Various authors have reported the more direct, positive correlations between the antioxidant ability results found after evaluation with different methods on a wide range of plant materials and food products [38].

It was also noted that the uniformity in the expression of the in vitro antioxidant activity of the food wastes based on the three methods is highly dependent upon the total phenol $(r=0.91$ to $0.998, p<0.05)$ and to some extent on the flavonoid content $(r=0.535$ to $0.633, p<0.05)$ irrespective of the type of solvent used for extraction. Conversely, correlation of flavonoid values with either one of the three methods was poor and not significant $(p>0.05)$ when the phenolic compounds are extracted using water. Additionally, no correlations were observed between the ascorbic acid content and the polyphenol profile of the food waste extracts ( $r=0.13$ to 0.28 , at $p<0.05$ ), in disagreement with the findings of Benammar et al. [52]. This is likely due to the use of a different reagent to extract vitamin C (trichloroacetic acid), as the type of extractant influences the extraction efficiency of bioactive compounds together with the antioxidant potential. With regard to any relationship between the antioxidant activity of onion peel extracts with the total phenol content, the correlation coefficient reported in the present study is in line with the range reported by Cioffi et al. [53] for olive pomace and Pinelo et al. [54] for grape pomace.

Regardless of the antioxidant activity assays, it is evident from Tables 1, 2 and 3 that food waste extracts with the highest total polyphenol content had higher antioxidant potential. Hence, the link between these two parameters was assessed and is presented in Fig. S1 for each of the extracts. This clearly shows the positive relationship between them irrespective of the methodologies used for all the three solvent types, with the strongest being for onion peel.

\subsection{Fatty acid and elemental composition of phytochemical-rich food wastes}

Results obtained by the GC-MS analysis of date seed, onion peel, pineapple skin and radish peel are presented in Fig. S2 and Table 3. In total 7, 6, 14 and 8 compounds were identified in onion peel, date seed, pineapple skin and radish peel, respectively. Fatty acids were the major portion of all the food waste samples, with essential polyunsaturated omega fatty acid-linoleic acid observed in onion peel, pineapple skin and radish peel. The majority constituent of onion peel was oxalic acid, followed by linoleic acid. Onion peel also constituted yet other 
Table 3 Overview of the major constituents of polyphenol-rich food wastes methanolic extracts as examined by GC

\begin{tabular}{|c|c|c|c|c|}
\hline Peak no & Rt (min) & Identified compound & Common name & Class \\
\hline \multicolumn{5}{|c|}{ (a) Onion peel } \\
\hline 1 & 5.019 & Ethanedioic acid, methyl ester (88\%) & Oxalic acid & Dicarboxylic acid \\
\hline 2 & 8.618 & Propanedioic acid, dimethyl ester (93\%) & Malonic acid & Dicarboxylic acid \\
\hline 3 & 20.186 & 2-Furancarboxaldehyde, 5-(hydroxymethyl) (91\%) & Hydroxymethylfurfural & Furans \\
\hline 4 & 29.862 & Tridecanoic acid, methyl ester (81\%) & Tridecylic acid & Saturated fatty acid \\
\hline 5 & 40.660 & Hexadecanoic acid, methyl ester (99\%) & Palmitic acid & Saturated fatty acid \\
\hline 6 & 44.602 & 9,12-Octadecadienoic acid (Z,Z)-methyl ester (99\%) & Linoleic acid & Omega-6 fatty acid (essential) \\
\hline 7 & 44.714 & 9-Octadecenoic acid (Z)-methyl ester (99\%) & Oleic acid & Monounsaturated omega-9 fatty acid \\
\hline \multicolumn{5}{|c|}{ (b) Date seed } \\
\hline 1 & 4.985 & Furfural (90\%) & Furan-2-carboxaldehyde & Heterocyclic aldehyde \\
\hline 2 & 20.172 & 2-Furancarboxaldehyde, 5-(hydroxymethyl) (83\%) & Hydroxymethylfurfural & Furans \\
\hline 3 & 29.856 & Dodecanoic acid, methyl ester (95\%) & Lauric acid & Saturated fatty acid \\
\hline 4 & 35.520 & Methyl tetradecanoate (96\%) & Myristic acid & Saturated fatty acid \\
\hline 5 & 40.653 & Hexadecanoic acid, methyl ester (98\%) & Palmitic acid & Saturated fatty acid \\
\hline 6 & 44.602 & 9,12-Octadecadienoic acid, methyl ester, $(\mathrm{E}, \mathrm{E})(99 \%)$ & Linolelaidic acid & Omega- 6 trans fatty acid \\
\hline \multicolumn{5}{|c|}{ (c) Pineapple skin } \\
\hline 1 & 5.062 & Ethanedioic acid, dimethyl ester (81\%) & Oxalic acid & Dicarboxylic acid \\
\hline 2 & 11.020 & Pentanoic acid, 4-oxo, methyl ester (90\%) & Levulinic acid & Keto acid \\
\hline 3 & 12.820 & Butanedioic acid, dimethyl ester (90\%) & Succinic acid & Dicarboxylic acid \\
\hline 4 & 16.517 & Dimethyl-dl-malate (83\%) & Malic acid & Dicarboxylic acid \\
\hline 5 & 19.234 & Thiophene, 3-4-diethyl (86\%) & Thiofuran & Heterocyclic aromatics \\
\hline 6 & 20.270 & 2-Furancarboxaldehyde, 5-hydroxymethyl) (95\%) & Hydroxymethylfurfural & Furans \\
\hline 7 & 36.087 & $\begin{array}{l}\text { 2-Propenoic acid, 2-(4-hydroxyphenyl)-, methyl ester } \\
\text { (93\%) }\end{array}$ & $\mathrm{p}$-Coumaric acid & Hydroxycinnamic acid \\
\hline 8 & 40.120 & Hexadecenoic acid, methyl ester (Z) (99\%) & Palmitoleic acid & Omega-7 monounsaturated fatty acid \\
\hline 9 & 44.609 & 9,12-Octadecadienoic acid $(Z, Z)$, methyl ester (99\%) & Linoleic acid & Omega- 6 fatty acid (essential) \\
\hline 10 & 44.756 & 9-Ocatdecenoic acid (Z), methyl ester (99\%) & Oleic acid & Monounsaturated omega-9 fatty acid \\
\hline 11 & 45.344 & Octadecanoic acid, methyl ester (99\%) & Stearic acid & Saturated fatty acid \\
\hline 12 & 49.650 & Eicosanoic acid, methyl ester (99\%) & Arachidic acid & Saturated fatty acid \\
\hline 13 & 53.62 & Docosanoic acid, methyl ester (98\%) & Behenic acid & Saturated fatty acid \\
\hline 14 & 57.317 & Tetracosanoic acid, methyl ester (99\%) & Lignoceric acid & Saturated fatty acid \\
\hline \multicolumn{5}{|c|}{ (d) Radish peel } \\
\hline 1 & 4.978 & Furfural (91\%) & Furan-2-carboxaldehyde & Heterocyclic aldehyde \\
\hline 2 & 8.577 & Propanedioic acid, dimethyl ester (90\%) & Malonic acid & Dicarboxylic acid \\
\hline 3 & 12.834 & Butanedioic acid, dimethyl ester (90\%) & Succinic acid & Dicarboxylic acid \\
\hline 4 & 16.517 & Dimethyl-dl-malate (83\%) & Malic acid & Dicarboxylic acid \\
\hline 5 & 40.66 & Hexadecanoic acid, methyl ester (98\%) & Palmitoleic acid & Omega-7 monounsaturated fatty acid \\
\hline 6 & 44.602 & 9,12-Octadecadienoic acid, methyl ester (98\%) & Linolelaidic acid & Omega- 6 trans fatty acid \\
\hline 7 & 44.749 & $\begin{array}{l}9,12,15-\text { Octadecatrienoic acid, methyl ester, }(Z, Z, Z)- \\
(99 \%)\end{array}$ & a-Linoleic acid & Omega-3 fatty acid (essential) \\
\hline 8 & 44.875 & 9-Octadecenoic acid (Z)-methyl ester (98\%) & Oleic acid & Monounsaturated omega-9 fatty acid \\
\hline
\end{tabular}

$R t$, retention time

Data in parenthesis indicate the per cent similarity of the compound to the existing database that was used to identify the compound

dicarboxylic acid (malonic acid) with furan (hydroxymethylfurfural) and (un)saturated fatty acids (tridecylic acid, palmitic acid and oleic acid). In date seed extracts, the six constituents represented furfural, hydroxymethylfurfural and saturated fatty acids (lauric, myristic, palmitic and linolelaidic acid). Fourteen compounds were identified in pineapple skin, which belonged to the class: 1. dicarboxylic acid (oxalic, succinic and malic acid). 2. keto acid (levulinic acid), 3. aromatics (Thiofuran), 4. furan (Hydroxymethylfurfural), 5 . hydroxycinnamic acid ( $p$-coumaric 
Table 4 Elemental composition of the polyphenol and essential fatty acid-rich food wastes

\begin{tabular}{lrlr}
\hline Element & Pineapple skin & Onion peel & Radish peel \\
\hline $\mathrm{N}(\mathrm{mg} / \mathrm{g})$ & $12.8 \pm 1.1$ & $3.4 \pm 1.1$ & $39.9 \pm 1.5$ \\
$\mathrm{P}(\mathrm{mg} / \mathrm{g})$ & $0.1 \pm 1.4$ & $0.2 \pm 1.6$ & $6.9 \pm 1.6$ \\
$\mathrm{~K}(\mathrm{mg} / \mathrm{g})$ & $0.5 \pm 1.9$ & $2.5 \pm 1.8$ & $39.6 \pm 1.2$ \\
$\mathrm{Ca}(\mathrm{mg} / \mathrm{g})$ & $2.2 \pm 1.9$ & $12.9 \pm 1.2$ & $5.5 \pm 1.2$ \\
$\mathrm{Mg}(\mathrm{mg} / \mathrm{g})$ & $0.7 \pm 3.2$ & $2.8 \pm 2.3$ & $2.6 \pm 1.5$ \\
$\mathrm{~S}(\mathrm{mg} / \mathrm{g})$ & $0.6 \pm 1.1$ & $0.9 \pm 1.2$ & $6.9 \pm 1.1$ \\
$\mathrm{Mn}(\mu \mathrm{g} / \mathrm{g})$ & $9.5 \pm 0.2$ & $59.3 \pm 2.3$ & $25.1 \pm 2.2$ \\
$\mathrm{Fe}(\mu \mathrm{g} / \mathrm{g})$ & $604.3 \pm 3.2$ & $27.0 \pm 2.0$ & $477.1 \pm 5.1$ \\
$\mathrm{Ni}(\mu \mathrm{g} / \mathrm{g})$ & $1.9 \pm 0.9$ & $0.03 \pm 1.0$ & $1.9 \pm 0.5$ \\
$\mathrm{Co}(\mu \mathrm{g} / \mathrm{g})$ & $0.3 \pm 1.7$ & $\mathrm{BDL}$ & $0.5 \pm 1.0$ \\
\hline
\end{tabular}

Values are means \pm standard deviation $(n=3)$

$\mathrm{BDL}$, below detection limit of ICP-MS (Co $=0.1 \mu \mathrm{g} / \mathrm{L})$

acid), 6. monounsaturated omega (palmitoleic and oleic acid), polyunsaturated omega-6 (linoleic acid) and saturated (stearic, archidic, behenic and lignoceric acid) fatty acids. One of the significant features is GC-MS analysis of the radish peel methanol extracts revealed that it is the major constituent of alpha-linoleic acid which is essential for humans and other animals $[55,56]$. With alpha-linoleic acid being the prime source, radish peel also constituted furfural, malonic acid, succinic acid, malic acid and unsaturated omega fatty acids like palmitoleic acid, linolelaidic acid and oleic acid.

ICP-MS analysis revealed that the high polyphenol and essential fatty acid constituting skins of onion, pineapple and radish are rich in essential micro- and macronutrients (Table 4). Pineapple skin and radish peel being the richest source of Fe. Notably, radish peel comprised a relatively higher level of essential elements than the other two showing its potential as a superior food waste which can be even used as an soil amendment or in compositing or as an substrate to develop nanofertilizer because of its reducing potential and chemical significance.

According to the obtained results, it is obvious that the peels from onion, pineapple and radish are not a waste, but a resource containing essential compounds and hence can be harnessed for food and pharmaceutical applications. Though a brief discussion of the food wastes oil extracts (for example, onion skin) for their chemical composition had been reported [57], a cumulative overview of the phytochemical profile of the predominant compounds of original food wastes as detailed in the current study is of significance. Our result on chemical profiling of date seed is in agreement with some other studies $[58,59]$ except where presence of furfural and linolelaidic acid is observed for the first time in this study.

\section{Conclusion}

This study provides new knowledge on the phytochemical properties and range for all the food waste classes employed and assists in identifying the most resourceful wastes. These new data are valuable additions to the database for the food processing, pharmaceutical, remedial and fertilizer industries and represent a significant step towards efficient waste management and economic return as value-added products. They will also assist to combat environmental threats via a green synthesis of nanoparticles and bioadsorbents against the pollutants. We recommend extracting, measuring and identifying the useful bioactive compounds of fruit and vegetable wastes. The screening of individual polyphenol constituents that exhibit health-promoting properties in onion peel, radish peel, pineapple skin and date seed requires further investigation.

Acknowledgements The support from the Indian government offered through DST-SERB (Department of Science and Technology-Science and Engineering Research Board) Ramanujan Fellowship grant (Sanction Order No. SB/S2/RJN-182/2017) is acknowledged.

\section{Compliance with ethical standard}

Conflict of interest The authors declare that they have no conflict of interest.

\section{References}

1. Gustavsson J, Cederberg C, Sonesson U, Van Otterdijk R, Meybeck A (2011) Global food losses and food waste. Food and Agriculture Organization of the United Nations, Rome, p 9

2. Pimentel D, Pimentel $M(2006)$ Global environmental resources versus world population growth. Ecol Econ 59:195-198

3. Peschel W, Sanchez-Rabaneda F, Diekmann W, Plescher A, Gartzia I, Jimenez D, Lamuela-Raventos R, Buxaderas S, Codina C (2006) An industrial approach in the search of natural antioxidants from vegetable and fruit wastes. Food Chem 97:137-150

4. Bustamante M, Said-Pullicino D, Paredes C, Cecilia J, Moral R (2010) Influences of winery-distillery waste compost stability and soil type on soil carbon dynamics in amended soils. Waste Manag 30:1966-1975

5. Yu R, Schellhorn HE (2013) Recent applications of engineered animal antioxidant deficiency models in human nutrition and chronic disease. J Nutri 143:1-11

6. Yan W, Lien HL, Koel BE, Zhang WX (2013) Iron nanoparticles for environmental clean-up: recent developments and future outlook. Environ Sci Process Impact 15:63-77

7. Kuppusamy S, Thavamani P, Megharaj M, Naidu R (2015) Bioremediation potential of natural polyphenol rich green wastes: a review of current research and recommendations for future directions. Environ Technol Innov 4:17-28

8. Kuppusamy S, Thavamani P, Megharaj M, Venkateswarlu K, Lee YB, Naidu R (2016) Oak (Quercus robur) acorn peel as a low-cost adsorbent for hexavalent chromium removal from aquatic ecosystems and industrial effluents. Water Air Soil Pollut 227:1-11 
9. Duthie GG, Duthie SJ, Kyle JA (2000) Plant polyphenols in cancer and heart disease: implications as nutritional antioxidants. Nutr Res Rev 13:79-106

10. Mazza M, Pomponi M, Janiri L, Bria P, Mazza S (2007) Omega-3 fatty acids and antioxidants in neurological and psychiatric diseases: an overview. Prog Neuropsychopharmacol Biol Psychiatry 31:12-26

11. Ma ZF, Zhang H (2017) Phytochemical constituents, health benefits, and industrial applications of grape seeds: a mini-review. Antioxidants 6:71

12. Valente T, Hidalgo J, Bolea I, Ramirez B, Angles N, Reguant J, Morello JR, Gutierrez C, Boada M, Unzeta M (2009) A diet enriched in polyphenols and polyunsaturated fatty acids, LMN diet, induces neurogenesis in the subventricular zone and hippocampus of adult mouse brain. J Alzheimer's Dis 18:849-865

13. Zhang Y, Seeram NP, Lee R, Feng L, Heber D (2008) Isolation and identification of strawberry phenolics with antioxidant and human cancer cell antiproliferative properties. J Agric Food Chem 56:670-675

14. Seeram NP, Adams LS, Zhang Y, Lee R, Sand D, Scheuller HS, Heber D (2006) Blackberry, black raspberry, blueberry, cranberry, red raspberry and strawberry extracts inhibit growth and stimulate apoptosis of human cancer cells in vitro. Agric Food Chem 54:9329-9339

15. Dai J, Mumper RJ (2010) Plant phenolics: extraction, analysis and their antioxidant and anticancer properties. Molecules 15:7313-7352

16. Chaudhary A, Bag S, Banerjee P, Chatterjee J (2017) Honey extracted polyphenolics reduce experimental hypoxia in human keratinocytes culture. J Agric Food Chem 65:3460-3473

17. Singleton V, Rossi JA (1965) Colorimetry of total phenolics with phosphomolybdic-phosphotungstic acid reagents. Am J Enol Vitic 16:144-158

18. Khomdram SD, Singh PK (2011) Polyphenolic compounds and free radical scavenging activity in eight Lamiaceae herbs of Manipur. Not Sci Biol 3:108-113

19. Yeo J, Shahidi $F(2020)$ Identification and quantification of soluble and insoluble-bound phenolics in lentil hulls and their antioxidant potential. Food Chem 315:126-202

20. Blois MS (1958) Antioxidant determinations by the use of a stable free radical. Nature 181:1199-1200

21. Oyaizu M (1986) Studies on products of browning reaction-antioxidative activities of products of browning reaction prepared from glucosamine. Jpn J Nutr 44:307-315

22. Prieto P, Pineda M, Aguilar M (1999) Spectrophotometric quantitation of antioxidant capacity through the formation of a phosphomolybdenum complex: specific application to the determination of vitamin E. Anal Biochem 269:337-341

23. Roe J, Kuether C (1943) Estimation of ascorbic acid. J Biol Chem 147:3999

24. Jiao Y, Chen D, Fan M, Quek SY (2019) UPLC-QqQ-MS/MS-based phenolic quantification and antioxidant activity assessment for thinned young kiwifruits. Food Chem 281:97-105

25. de Oliveira AC, Valentim IB, Silva CA, Bechara EJH, Barros MPd, Mano CM, Goulart MOF (2009) Total phenolic content and free radical scavenging activities of methanolic extract powders of tropical fruit residues. Food Chem 115:469-475

26. Singh B, Singh JP, Kaur A, Singh N (2018) Phenolic compounds as beneficial phytochemicals in pomegranate (Punica granatum L.) peel: a review. Food Chem 261:75-86

27. Lee KA, Kim KT, Nah SY, Chung MS, Cho S, Paik HD (2011) Antimicrobial and antioxidative effects of onion peel extracted by the subcritical water. Food Sci Biotechnol 20:543-548

28. Singh BN, Singh B, Singh R, Prakash D, Singh D, Sarma B, Upadhyay G, Singh H (2009) Polyphenolics from various extracts/ fractions of red onion (Allium cepa) peel with potent antioxidant and antimutagenic activities. Food Chem Toxicol 47:1161-1167

29. Skerget M, Majhenic L, Bezjak M, Knez Z (2009) Antioxidant, radical scavenging and antimicrobial activities of red onion (Allium cepa L) skin and edible part extracts. Chem Biochem Eng Q 23:435-444

30. Obied HK, Bedgood JDR, Prenzler PD, Robards K (2008) Effect of processing conditions, prestorage treatment, and storage conditions on the phenol content and antioxidant activity of olive mill waste. J Agric Food Chem 56:3925-3932

31. Ardekani MRS, Khanavi M, Hajimahmoodi M, Jahangiri M, Hadjiakhoondi A (2010) Comparison of antioxidant activity and total phenol contents of some date seed varieties from Iran. Iran J Pharm Res 9:141

32. Kalpna R, Mital K, Sumitra C (2011) Vegetable and fruit peels as a novel source of antioxidants. J Med Plant Res 5:63-71

33. Singh N, Rajini $P$ (2004) Free radical scavenging activity of an aqueous extract of potato peel. Food Chem 85:611-616

34. Lu X, Rasco BA, Jabal JM, Aston DE, Lin M, Konkel ME (2011) Investigating antibacterial effects of garlic (Allium sativum) concentrate and garlic-derived organosulfur compounds on Campylobacter jejuni by using Fourier transform infrared spectroscopy, Raman spectroscopy, and electron microscopy. Appl Environ Microbiol 77:5257-5269

35. Liu Q, Tang GY, Zhao CN, Feng XL, Xu XY, Cao SY, Meng X, Li S, Gan RY, Li HB (2018) Comparison of antioxidant activities of different grape varieties. Molecules 23:2432

36. Adamczak A, Ożarowski M, Karpiński TM (2020) Antibacterial activity of some flavonoids and organic acids widely distributed in plants. J Clin Med 9:109

37. Mangang KCS, Chakraborty S, Deka SC (2020) Optimized microwave-assisted extraction of bioflavonoids from Albizia myriophylla bark using response surface methodology. J Food Sci Technol. https://doi.org/10.1007/s13197-020-04246-3

38. Anwar F, Przybylski R (2012) Effect of solvents extraction on total phenolics and antioxidant activity of extracts from flaxseed (Linum usitatissimum L.). Acta Sci Pol Technol Aliment 11:293-301

39. Beato VM, Sanchez AH, de Castro A, Montaño A (2012) Effect of processing and storage time on the contents of organosulfur compounds in pickled blanched garlic. J Agric Food Chem 60:3485-3491

40. Bursal E, Aras A, Kılıç Ö, Buldurun K (2020) Chemical constituent and radical scavenging antioxidant activity of Anthemis kotschyana Boiss. Nat Prod Res. https://doi.org/10.1080/14786 419.2020.1723089

41. Staszowska-Karkut M, Materska M (2020) Phenolic composition, mineral content, and beneficial bioactivities of leaf extracts from black currant (Ribes nigrum L.), raspberry (Rubus idaeus) and aronia (Aronia melanocarpa). Nutrients 12:463

42. Brand-Williams W, Cuvelier M, Berset C (1995) Use of a free radical method to evaluate antioxidant activity. LWT Food Sci Technol 28:25-30

43. Erol NT, Sari F, Polat G, Velioglu YS (2009) Antioxidant and antibacterial activities of various extracts and fractions of fresh tea leaves and green tea. Tarim Bilim Derg 15:371-378

44. Krisch J, Galgoczy L, Papp T, Csaba Vagvolgyi C (2009) Antimicrobial and antioxidant potential of waste products remaining after juice pressing. J Eng Ann Fac Eng Hunedoara 7:131-134

45. Singh N, Rajini P (2008) Antioxidant-mediated protective effect of potato peel extract in erythrocytes against oxidative damage. Chem Biol Interact 173:97-104

46. Abdeltaif SA, SirElkhatim KA, Hassan AB (2018) Estimation of phenolic and flavonoid compounds and antioxidant activity of spent coffee and black tea (processing) waste for potential recovery and reuse in Sudan. Recycling 3:27 
47. Alaa A, Abdulhakim A, Rawaa T (2019) Potato and tomato peel extract-a natural antioxidant for retarding lipid peroxidation in lamb meat (Awassi) refrigerator storage. J Food Nutri Agric 2:1-5

48. Sands KN, Back TG (2018) Key steps and intermediates in the catalytic mechanism for the reduction of peroxides by the antioxidant ebselen. Tetrahedron 74:4959-4967

49. Pereira MC, Oliveira DA, Hill LE, Zambiazi RC, Borges CD, Vizzotto M, Mertens-Talcott S, Talcott S, Gomes CL (2018) Effect of nanoencapsulation using PLGA on antioxidant and antimicrobial activities of guabiroba fruit phenolic extract. Food Chem 240:396-404

50. Hiremath VM, Jain R, Jain N, Arora A, Swaroop K, Singh MK, Kumar P, Kumar G (2018) Quantification of total endogenous ascorbic acid from chrysanthemum (Chrysanthemum $\times$ morifolium) cultivars and its association with postharvest life. Ind J Agric Sci 88:1429-1433

51. Dudonne S, Vitrac X, Coutiere P, Woillez M, Merillon JM (2009) Comparative study of antioxidant properties and total phenolic content of 30 plant extracts of industrial interest using DPPH, ABTS, FRAP, SOD, and ORAC assays. J Agric Food Chem 57:1768-1774

52. Benammar C, Hichami A, Yessoufou A, Simonin AM, Belarbi M, Allali H, Khan NA (2010) Zizyphus lotus L.(Desf.) modulates antioxidant activity and human T-cell proliferation. BMC Complement Altern Med 10:54

53. Cioffi G, Pesca MS, De Caprariis P, Braca A, Severino L, De Tommasi N (2010) Phenolic compounds in olive oil and olive pomace from Cilento (Campania, Italy) and their antioxidant activity. Food Chem 121:105-111
54. Pinelo $M$, Rubilar $M$, Jerez $M$, Sineiro J, Nunez MJ (2005) Effect of solvent, temperature, and solvent-to-solid ratio on the total phenolic content and antiradical activity of extracts from different components of grape pomace. J Agric Food Chem 53:2111-2117

55. Williams CM (2000) Dietary fatty acids and human health. Ann Zootech 49:165-180

56. Juneja LR, Wilczynska A, Singh RB, Takahashi T, Pella D, Chibisov S, Abramova M, Hristova K, Fedacko J, Pella D, Wilson DW (2019) Evolutionary diet and evolution of man. In: Singh RB, Watson RR, Takahashi T (eds) The role of functional food security in global health, Academic Press, pp 71-85

57. Bello M, Olabanji I, Abdul-Hammed M, Okunade T (2013) Characterization of domestic onion wastes and bulb (Allium cepa L.): fatty acids and metal contents. Int Food Res J 20:2153-2158

58. Al-Shahib W, Marshall RJ (2003) The fruit of the date palm: its possible use as the best food for the future? Int J Food Sci Nutr 54:247-259

59. Besbes S, Blecker C, Deroanne C, Drira NE, Attia H (2004) Date seeds: chemical composition and characteristic profiles of the lipid fraction. Food Chem 84:577-584

Publisher's Note Springer Nature remains neutral with regard to jurisdictional claims in published maps and institutional affiliations. 